\title{
Pediatric rheumatology: addressing the transition to adult-orientated health care
}

This article was published in the following Dove Press journal: Open Access Rheumatology: Research and Reviews

\author{
Sara Sabbagh ${ }^{1,2}$ \\ Tova Ronis ${ }^{1,3}$ \\ Patience HWhite ${ }^{3-5}$ \\ 'Department of Rheumatology, \\ Children's National Health \\ System, Washington DC, USA; \\ ${ }^{2}$ National Institute of Arthritis and \\ Musculoskeletal and Skin Diseases, \\ National Institutes of Health, \\ Bethesda, MD USA; ${ }^{3}$ Department \\ of Pediatrics, George Washington \\ University School of Medicine and \\ Health Sciences, Washington DC, \\ USA; ${ }^{4}$ Department of Rheumatology, \\ George Washington University School \\ of Medicine and Health Sciences, \\ Washington DC, USA; ${ }^{5}$ Department \\ of Medicine, George Washington \\ University School of Medicine and \\ Health Sciences, Washington DC, USA
}

Correspondence: Patience H White Department of Pediatrics and Medicine, George Washington University School of Medicine and Health Sciences, I6I5 M Street, NW Suite 290, Washington, DC, 20036, USA

$\mathrm{Tel}+\mathrm{I} 2022231500$

Fax + I 2024293957

Email pwhite@thenationalalliance.org

\begin{abstract}
The transition from pediatric to adult health care is often a challenging process due to multiple interwoven complexities, especially for children with chronic medical conditions. Health care transition (HCT) is a process of moving from a pediatric to an adult model of health care with or without a transfer to a new clinician. This paper focuses on what is known about HCT for youth and young adults (Y/YA) with rheumatic diseases within a larger context of HCT recommendations. HCT barriers for youth, families, and providers and current evidence for a structured HCT processes are reviewed. Practical advice is offered on how to approach transition for Y/YA, what tools are available to assist in a successful transition process, and what are the areas of future research that are needed to improve the HCT evidence base.
\end{abstract}

Keywords: health care transition, pediatric rheumatology, special health care needs, transition, transition readiness assessment

\section{Introduction and background}

The transition from pediatric to adult health care is often a challenging process due to multiple interwoven complexities, especially for children with chronic medical conditions. Historically, transition has been characterized by an unsystematic or disorganized transfer of care. Health care transition (HCT) is not just the act of transfer but is the process over time of moving from a pediatric to an adult model of health care with or without transfer to a new clinician. The goals of transition are 1) to improve the ability of youth and young adults (Y/YA) to manage their own health and effectively use health services and 2) to have an organized clinical process in pediatric and adult practices to facilitate transition preparation, transfer of care, and integration into adultcentered care. ${ }^{1}$ Patients with special health care needs (SHCN) require increased care and attention, making the transition process more complex. This paper focuses on what is known about HCT for Y/YA with rheumatic diseases within a larger context of HCT recommendations and does not discuss education or vocation, two other important transition components.

It is estimated that there are 18 million adolescents in the USA, of which $\sim 4.5$ million have chronic medical conditions. ${ }^{2}$ The need for a coordinated systematic transition of care from pediatric to adult providers has increased as advances in health care have facilitated decline in morbidity and mortality of children with chronic medical conditions. More than $90 \%$ of children with SHCN are now projected to survive to adulthood and require transitional services. ${ }^{3}$ 
Both healthy children and those with chronic illnesses experience multiple barriers to successful transition. One such barrier is the lack of transition support that youths experience in transition of care. The 2016 National Survey for Children's Health of parents of Y/YA aged 12-17 years reports that $83 \%$ of youth with SHCN and $86 \%$ of youth without SHCN did not receive adequate transition support. ${ }^{4}$ Other surveys analyzing transitional needs of youth with juvenile idiopathic arthritis (JIA) and their parents reported a negative transfer experience and stressed the need for increased coordination of care, provider continuity, visit privacy, and an age-appropriate approach to transition of care. ${ }^{5}$ A systematic review of patients' attitudes and experiences of transitional care indicated that some patients feel de-personalized, abandoned, ill-prepared, and not in control of their transition process. ${ }^{6}$

During transition to adult care, there is also a tendency toward increased disease activity. Approximately half of young people with juvenile onset rheumatic arthritis enter adulthood with active disease or develop disease flares as YA. ${ }^{78}$ In patients with childhood onset of systemic lupus erythematosus (SLE), there is evidence of increased disease activity in the year following transition. ${ }^{9}$ Patients with chronic rheumatic diseases often require long-term treatment with immunosuppressive therapies and are at significant risk of increased disability and morbidity if their care is interrupted during transition. Studies suggest that patients transitioning to an adult rheumatology practice experience significant delays in their first adult visit, which may adversely impact medication adherence and clinic visit show rates. ${ }^{10}$ Unfortunately, there is evidence that up to half of young patients do not complete a successful transfer to adult rheumatology, increasing their risk of poor outcomes. ${ }^{9,11}$ In addition to experiencing gaps in care during transfer, youths are at risk of withdrawing from health care services altogether. Furthermore, patients often need increased emotional and mental health support during the transition period. For instance, youths with SLE have shown notable anxiety and depression in the post-transition period. ${ }^{12}$ Last, many adolescents and young adults lack important self-management and health care utilization skills needed for the transfer to adult care. ${ }^{13-15}$

Lack of clinicians' knowledge regarding transition processes and available resources, decreased access to patient information, and lack of adequate communication, funding, and time are all additional barriers to transition. A survey of pediatric rheumatologists in the Childhood Arthritis and Rheumatology Research Alliance and a survey of transition practices and attitudes among adult rheumatologists in the American College of Rheumatology (ACR) revealed low provider familiarity with transition resources and recommendations, inadequate training in the transition issues of YA, and lack of the necessary time and available personnel to facilitate the transition process. ${ }^{16,17}$ Insufficient communication between pediatric and adult providers can impede successful transition and decrease the quality of patient care. As part of the ACR survey, nearly half of the adult providers reported dissatisfaction with the patient information they received from the pediatric provider. In the USA, funding of transition services proves to be another barrier to successful transfer of care. Last, the implementation of a systematic transition process requires a significant dedication of clinician and care-manager time, especially for youth with socially and medically complex conditions. ${ }^{18}$

\section{Transition process for practices/ systems}

Studies have shown that having a structured transition method can significantly improve transition processes and outcomes. ${ }^{19}$ Currently, there are multiple transition models which, although variable in their structure and provider roles, often align across broad categories of processes to improve transition for youth with and without SHCN. These HCT processes are 1) preparation, 2) transfer of care, and 3) integration into adult health care.

In 2011, the American Academy of Pediatrics (AAP), the American Academy of Family Practitioners (AAFP), and the American College of Physicians (ACP) joined together to outline their suggested HCT approach in a clinical report called Supporting the Health Care Transition from Adolescence to Adulthood in the Medical Home. It provides an approach to HCT including the need to assess transition skill readiness and patient education, preparation of a medical summary, and communication between the pediatric and the adult health care providers. ${ }^{20}$ The report outlines a decision-making algorithm for managing the transition process. Got Transition, the national center for HCT, developed a structured approach called the Six Core Elements of HCT to help to implement the recommendations of the AAP, AAFP, ACP clinical reports. ${ }^{21}$ The Six Core Elements of HCT have been shown to improve HCT process in primary, ${ }^{22}$ subspecialty, ${ }^{23}$ and Medicaid managed care, ${ }^{18}$ as well as children's hospital clinical settings. ${ }^{24}$ Providers can decide which of the core elements to be implemented based on the needs of their patients' and the practices' available resources. Implementing a systematic method of 
transition for patients with rheumatologic disease is essential in achieving a successful transfer of care; however, the process must be individualized to each patient. Children with rheumatic disease have a wide range of transition needs based on multiple factors such as disease activity, readiness, cognitive and executive functioning proficiency, home support structures, and socioeconomic factors. For instance, a child with mild disease, minimal to no disease morbidity, stable social environment, and excellent accesses to resources will require much less assistance in the transition process. This contrasts with a child who comes from an unstable socioeconomic background and has severe disease with multiorgan involvement who requires multiple medications and management by several subspecialty providers. In the latter scenario, the rheumatology practice would employ all of the Six Core Element processes.

The Six Core Elements of HCT address the preparation, transfer, and integration phases of transition and are broken down into a transition policy, tracking and monitoring, readiness assessment, transition planning, transfer of care, and transfer completion. Three different packages with tools for each core element are available; for those caring for youth who will transfer to an adult practice, for those who will move to an adult model of care without changing their provider, and for those who will be accepting young adults into their practice. Table 1 shows the Six Core Elements for youth transitioning to an adult health care provider. Figure 1 demonstrates how the Six Core Elements can be applied within a practice setting over the transition planning and transfer process. In this study, each of the elements are discussed from a rheumatological point of view. To assist with implementation of the Six Core Elements of HCT, the ACR joined the ACP Pediatric to Adult Care Transitions Initiative and formed the ACR Transition Work Group. They developed a subspecialty-specific toolkit ${ }^{72}$ tailored to pediatric and adult rheumatologists to assist them in transitioning their patients.

Table I Contents of the Six Core Elements for "Youth Transitioning to Adult Care"

\begin{tabular}{|c|c|}
\hline & $\begin{array}{l}\text { - Develop a transition policy/statement with input from youths and families that describes the practice's approach to } \\
\text { transition, including privacy and consent information } \\
\text { - Educate all staff about the practice's approach to transition, the policy/statement, the Six Core Elements, and distinct roles of } \\
\text { the youth, family, and pediatric and adult health care team in the transition process, taking into account cultural preferences } \\
\text { - Post policy publicly and share/discuss with youths and families, beginning at the age of I2-I4 years, and regularly review as } \\
\text { part of ongoing care }\end{array}$ \\
\hline $\begin{array}{l}\text { 2. Transition } \\
\text { tracking and } \\
\text { monitoring }\end{array}$ & $\begin{array}{l}\text { - Establish criteria and process for identifying transitioning youths and enter their data into a registry } \\
\text { - Use individual flow sheet or registry to track youth's transition progress with the Six Core Elements } \\
\text { - Incorporate Six Core Elements into clinical care process, using electronic medical record if possible }\end{array}$ \\
\hline $\begin{array}{l}\text { 3. Transition } \\
\text { readiness }\end{array}$ & $\begin{array}{l}\text { - Conduct regular transition readiness assessments, beginning at the age of } 14 \text { years, to identify and discuss with youth and } \\
\text { parent/caregiver their needs and goals in self-care and how to use the adult health care system } \\
\text { - Jointly develop goals and prioritized actions with youth and parent/caregiver and document regularly in a plan of care }\end{array}$ \\
\hline $\begin{array}{l}\text { 4. Transition } \\
\text { planning }\end{array}$ & $\begin{array}{l}\text { - Develop and regularly update the plan of care, including readiness assessment findings, goals and prioritized actions, medical } \\
\text { summary and emergency care plan, and, if needed, a condition fact sheet and legal documents } \\
\text { - Prepare youth and parent/caregiver for adult approach to care at the age of I8 years, including legal changes in decision } \\
\text { making and privacy and consent, self-advocacy, and access to information } \\
\text { - Determine need for decision-making supports for youth with intellectual challenges and make referrals to legal resources } \\
\text { - Plan with youth and parent/caregiver for optimal timing of transfer. If both primary and subspecialty care are involved, discuss } \\
\text { optimal timing for each } \\
\text { - Obtain consent from youth/guardian for the release of medical information } \\
\text { - Assist youth in identifying an adult provider and communicate with selected provider about pending transfer of care } \\
\text { - Provide referrals to insurance resources, self-care management information, and culturally appropriate community supports }\end{array}$ \\
\hline 5. Transfer of care & $\begin{array}{l}\text { - Confirm date of first adult provider appointment } \\
\text { - Transfer young adult when his/her condition is stable } \\
\text { - Complete transfer package, including final transition readiness assessment, plan of care with transition goals and pending } \\
\text { actions, medical summary and emergency care plan, and, if needed, legal documents, condition fact sheet, and additional } \\
\text { provider records } \\
\text { - Prepare letter with transfer package, send to adult practice, and confirm adult practice's receipt of transfer package } \\
\text { - Confirm with adult provider the pediatric provider's responsibility for care until young adult is seen in adult setting }\end{array}$ \\
\hline $\begin{array}{l}\text { 6. Transfer } \\
\text { completion }\end{array}$ & $\begin{array}{l}\text { - Contact young adult and parent/caregiver 3-6 months after last pediatric visit to confirm transfer of responsibilities to adult } \\
\text { practice and elicit feedback on experience with transition process } \\
\text { - Communicate with adult practice confirming completion of transfer and offer consultation assistance, as needed } \\
\text { - Build ongoing and collaborative partnerships with adult practices }\end{array}$ \\
\hline
\end{tabular}

Note: Data from www.gottransition.org.' 


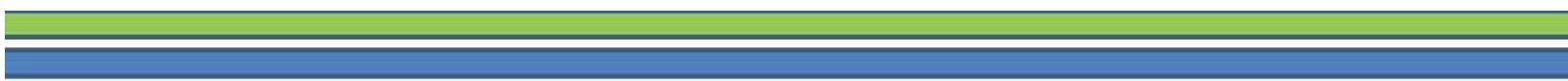

Six core element approach to health care transition

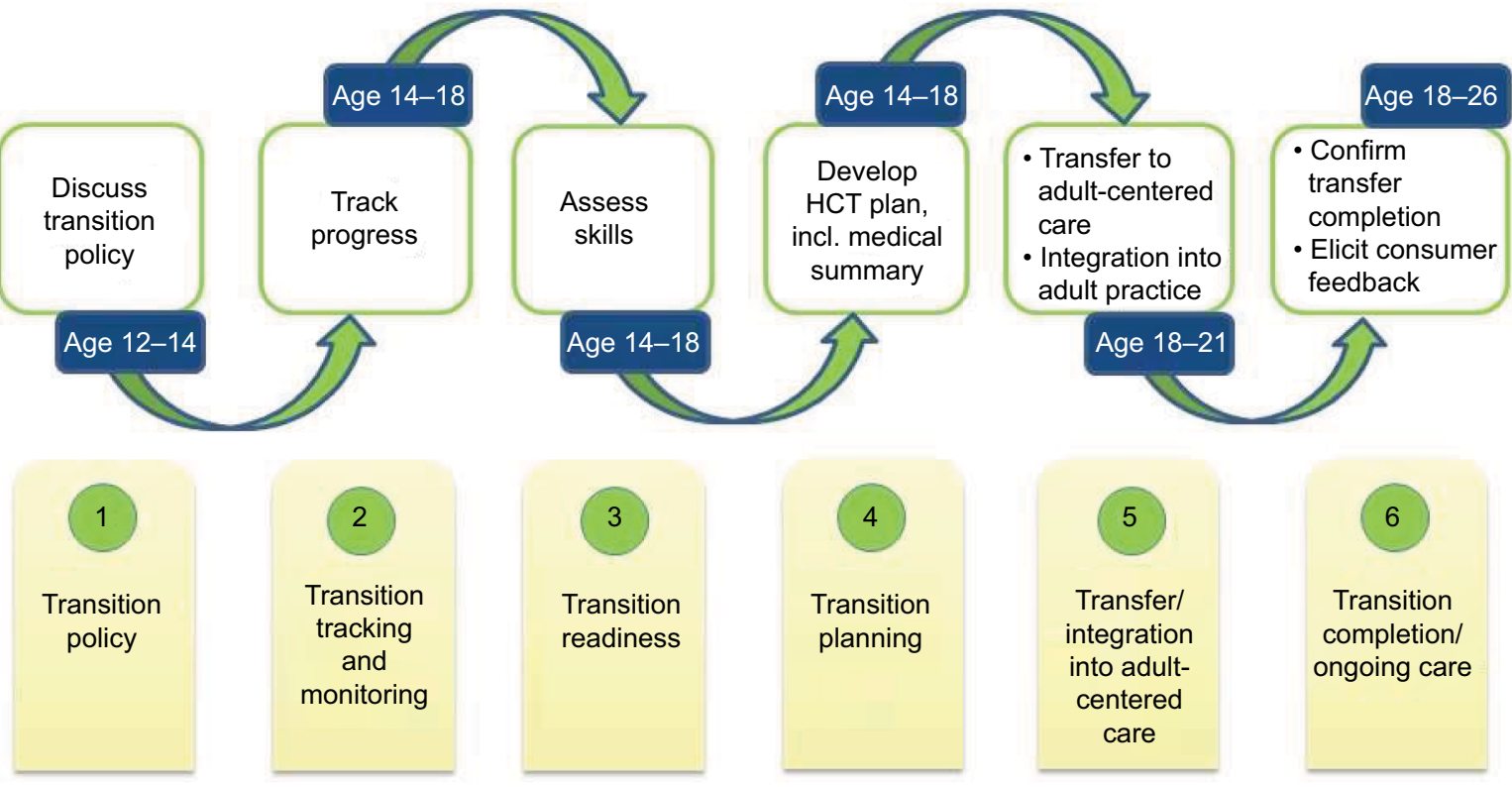

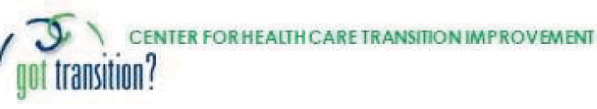

Figure I Six Core Element approach to health care transition (HCT). Note: Data from www.gottransition.org.'

\section{Policy}

The ACR Transition Work Group recommends that each pediatric rheumatology practice develops a transition policy to share with patients and their families, which can be customized by the provider for their practice. As part of the adult rheumatologist toolkit, the ACR endorses using a patient welcome letter as part of their transition policy. Having a transition policy allows both the youth and the family to understand the transition process in the practice (when it starts, when they are expected to find an adult provider, what support the practice will offer during the process) and know what is expected of them. It can be challenging for providers developing the policy to agree on the practices' HCT process, decide when and how to share the policy with their patients, and how to ensure all providers follow it. Y/YA and their families state that knowing the process and their roles in it makes transition easier and less stressful for all involved.

\section{Tracking and monitoring}

The second element of the Six Core Elements of HCT is establishing a mechanism to track the progress of each individual patient as they advance through the transition process. It is recommended to use an individual flowchart to track each patient's progress and to use the electronic medical record (EMR) to monitor the transition process of a larger population. For example, a HCT registry was developed during a pilot study by Got Transition and a Washington DC-based managed care plan, Health Services for Children with Special Needs (HSCSN) to assess the effectiveness of customizing and incorporating recommended transition services into a Medicaid managed care plan. ${ }^{18}$ The tracking process for individual patients was implemented by using a HSCSN nurse care manager and an AmeriCorps volunteer to reach out to participants, highlighting the importance of a multidisciplinary team to support the transition process. The importance of a team-based approach in tracking patient 
progress was also emphasized in feedback interviews for a quality improvement (QI) model to apply systematic clinical transition practices in primary care clinics. ${ }^{22}$ The QI HCT model effectively implemented the Six Core Elements of HCT and developed written registries to track transitioning youth at all sites. A QI initiative at Texas Children's Hospital used an EMR-based transition planning tool for youth with SHCN and found that nurses and case managers were the top users, ${ }^{25}$ underscoring the importance of a team-based approach. Additional efforts to integrate HCT into EMRs to improve patient tracking are needed.

\section{Readiness assessment}

A fundamental element of the HCT process is preparing Y/YA to manage their own health, as reported in a recent review. ${ }^{26}$ This involves the Y/YA, the family, and the provider as equally engaged collaborators. By using a transition readiness assessment, providers can evaluate patients' selfmanagement abilities. Skills in navigating the health care system and taking responsibility for managing their own health are particularly important for those individuals with chronic illnesses. There have been several validated methods for evaluating transition readiness in patients with various chronic conditions. As part of developing more reliable transition processes, the AAP, AAFP, and ACP guidelines suggest that providers should regularly assess transition readiness by using an objective measure. The tools should be used to learn which skills the youth need to improve their self-management and, for caregivers, to learn which skills they need to help their youth attain. To date, none of the readiness assessment tools have been shown to predict a successful transition.

Several transition readiness assessments were reviewed by completing a literature search under PubMed with combinations of the following terms: transition readiness, assessment, questionnaire, chronic illness, condition, pediatric, and adolescent. Of those reviewed, the readiness assessments discussed below and outlined in Table 2 were most frequently cited for use in children with chronic illness. There are also several non-rheumatology disease-specific readiness assessments that are not discussed here, but reviewed elsewhere. ${ }^{27,28}$ In addition, we included one rheumatology-specific readiness assessment in our discussion.

1. Got Transition readiness assessment is included in the pediatric rheumatology ACR transition toolkit. The Got Transition readiness assessment scale involves rating transition importance and youth confidence as well as questions regarding patient knowledge of their health and their ability to use and navigate the health care system. Assessing confidence is an important way to evaluate $\mathrm{Y} /$ YA engagement in their health, which has been shown to improve health outcomes and is a key issue in this age group. ${ }^{29}$ The Got Transition readiness assessment was used in several HCT QI projects with successful implementation at all sites. ${ }^{18,22-24}$ It is available in two forms, one for youth and one for parents, is customizable, available in Spanish, and does not require a provider for administration. ${ }^{1}$

2. The Transition Readiness Assessment Questionnaire $(T R A Q)^{30}$ is also included in the ACR toolkit. The TRAQ is a 29-item patient-reported assessment that focuses on two domains: self-management and self-advocacy. It is one of the few available validated, patient-reported, and disease-non-specific transition readiness tools and does not require a provider to administer it. In a study of patients with pediatric-onset chronic health conditions, TRAQ scores were shown to be positively associated with age and typically higher in females. ${ }^{31}$ Another study reinforces the existing data that young adolescents are often not prepared for transition. ${ }^{15}$ There have been theorized inadequacies of the TRAQ assessment, including the notion that the TRAQ has a "ceiling effect" in which its utility decreases in individuals with higher scores. ${ }^{32}$ In addition, it may not be an adequate measure of readiness in younger adolescents. ${ }^{33}$

3. TRxANSITION Index (formerly TRxANSITION Scale) is a readiness assessment that, unlike the other tools, requires a staff member to administer. The assessment is performed via semistructured interviews, and responses are verified by referring to the patients' medical records. It comprises 32 items across 10 domains, including Type of chronic health condition, $\mathrm{Rx} /$ medications, Adherence, Nutrition, Self-management, Issues of reproduction, Trade/school, Insurance, Ongoing support, and New health providers. ${ }^{34}$ The STARx (Self-Management and Transition to Adulthood with $\mathrm{Rx}=$ Treatment) is a selfreported questionnaire developed to gather information on self-management and HCT skills in youth with chronic health conditions and is complementary to the TRxANSITION Index. It has 18 questions that cover three domains and has been internally validated..$^{35,36}$

4. The On Taking Responsibility for Adolescent/Adult Care (ON TRAC) transition model is a self-administered 
Table 2 Readiness assessments

\begin{tabular}{|c|c|c|c|c|c|}
\hline Assessment & Validated? & $\begin{array}{l}\text { How many } \\
\text { questions? }\end{array}$ & $\begin{array}{l}\text { Who } \\
\text { administers? }\end{array}$ & Content & Customizable? \\
\hline $\begin{array}{l}\text { Got Transition: Transitional } \\
\text { Readiness Assessment }\end{array}$ & No & 25 questions & $\begin{array}{l}\text { Self-administered; } \\
\text { parent and patient } \\
\text { forms }\end{array}$ & $\begin{array}{l}\text { Patient knowledge of health } \\
\text { Ability to navigate system }\end{array}$ & Yes \\
\hline $\begin{array}{l}\text { Transition Readiness } \\
\text { Assessment Questionnaire } \\
\text { (TRAQ) }\end{array}$ & Yes & 29 questions & $\begin{array}{l}\text { Patient self- } \\
\text { administers }\end{array}$ & $\begin{array}{l}\text { Self-management skills } \\
\text { Self-advocacy }\end{array}$ & No \\
\hline TRxANSITION & Yes & $\begin{array}{l}32 \text { questions; } \\
\text { semistructured } \\
\text { interview } \\
\text { format }\end{array}$ & $\begin{array}{l}\text { Administered by } \\
\text { clinic staff }\end{array}$ & $\begin{array}{l}\text { Type of chronic health condition } \\
\text { Rx/medications } \\
\text { Adherence } \\
\text { Nutrition } \\
\text { Self-management skills } \\
\text { Issues of reproduction } \\
\text { Trade/school } \\
\text { Insurance } \\
\text { Ongoing support } \\
\text { New health care providers }\end{array}$ & No \\
\hline $\begin{array}{l}\text { Self-Management and } \\
\text { Transition to Adulthood with } \\
\mathrm{Rx}=\text { Treatment (STARx) }\end{array}$ & Yes & 18 questions & $\begin{array}{l}\text { Patient self- } \\
\text { administers }\end{array}$ & $\begin{array}{l}\text { Medication management } \\
\text { Provider communication } \\
\text { Engagement during appointments } \\
\text { Disease knowledge } \\
\text { Adult health responsibilities } \\
\text { Resource utilization }\end{array}$ & No \\
\hline $\begin{array}{l}\text { ON Taking Responsibility for } \\
\text { Adolescent/Adult Care (ON } \\
\text { TRAC) }\end{array}$ & Yes & 25 questions & $\begin{array}{l}\text { Patient self- } \\
\text { administers }\end{array}$ & $\begin{array}{l}\text { Self-advocacy and self-esteem } \\
\text { Self-management health care behaviors } \\
\text { Sexual health } \\
\text { Social supports } \\
\text { Vocational planning }\end{array}$ & No \\
\hline TRANSITION-Q & Yes & 14 questions & $\begin{array}{l}\text { Patient self- } \\
\text { administers }\end{array}$ & $\begin{array}{l}\text { Self-management skills in health and health } \\
\text { care }\end{array}$ & No \\
\hline $\begin{array}{l}\text { California Healthy and Ready } \\
\text { to Work (CA HRTW) }\end{array}$ & Yes & $\begin{array}{l}90 \text { patient } \\
\text { questions } \\
72 \text { parent } \\
\text { questions }\end{array}$ & $\begin{array}{l}\text { Self-administered; } \\
\text { parent and patient } \\
\text { forms }\end{array}$ & $\begin{array}{l}\text { Disease knowledge/management } \\
\text { Preventative health behaviors } \\
\text { Emergency measures } \\
\text { Environmental accommodations } \\
\text { Monitoring of health condition } \\
\text { Management of health condition } \\
\text { Communication } \\
\text { Community resources } \\
\text { Responsible sexual activity } \\
\text { Health records } \\
\text { Health insurance } \\
\text { Accommodations } \\
\text { Developmental needs } \\
\text { Transportation }\end{array}$ & No \\
\hline $\begin{array}{l}\text { Rheumatology-specific } \\
\text { transition readiness skills } \\
\text { (RACER) }\end{array}$ & No & 32 questions & $\begin{array}{l}\text { Patient self- } \\
\text { administers }\end{array}$ & $\begin{array}{l}\text { Planning for adult life } \\
\text { Self-advocacy } \\
\text { Health service navigation } \\
\text { Health condition management }\end{array}$ & No \\
\hline
\end{tabular}

questionnaire for assessing transition readiness. Its objective was to provide a transition planning program that was based on self-management. It is divided developmentally into three age-specific transition stages that address six domains of transition: 1) self-advocacy and self-esteem, 2) independent/self-management health care behaviors,
3) sexual health, 4) social supports, 5) educational, vocational, and financial planning, and 6) health and lifestyle. ${ }^{37}$

5. The TRANSITION-Q is a self-administered readiness scale that is used to measure health care management skills. It has been designed using Rasch measurement theory analysis to apply a modern psychometric approach 
of assessing transition readiness, does not focus on other self-management skills such as education or vocation, and has been used in children with different chronic health conditions. $^{38}$

6. The California Healthy and Ready to Work (CA HRTW) Transition Assessment Tool measures the overall transition readiness reported by both patient and parent and is based on 14 domains including patient knowledge of condition, disease management, ability to navigate the health care system, communication, community resources, sexual health, transportation, and developmental needs. ${ }^{39,40}$ Guidelines using HRTW for teaching youth with SHCN health and self-care skills were based on the developmental frameworks of Piaget and Inhelder ${ }^{42}$ and Erikson ${ }^{41}$ and self-care models of Orem. ${ }^{43}$ It has established content validity; ${ }^{40}$ however, a pilot study assessing the CA HRTW Transition Assessment Tool found it had low internal consistency for many domains. This may have been attributed to limited range of responses and low samples size. ${ }^{44}$ It has also been used in Y/YA with chronic rheumatic disease with data suggesting that older patients were more able to navigate the health care system but did not demonstrate an increased proficiency in medication management. $^{45}$

7. The Readiness for Adult Care in Rheumatology (RACER) questionnaire is a self-administered rheumatology-specific assessment. It was developed to measure transition readiness, assess gaps in youths' knowledge and preparedness, recognize areas in need of additional support, and evaluate efficacy of transition interventions. After consensus agreement, four domains were incorporated into the RACER questionnaire, including 1) planning for adult life, 2) self-advocacy, 3) health service navigation, and 4 ) health condition management. ${ }^{46}$

Self-management is cited as a central skill needed for transition readiness. Parental support for the development of their youth's self-management skills and their ability to make independent health care decisions are outlined in a recent literature review by Burke et al. ${ }^{26}$ The possession of selfmanagement skills is often dictated by executive functioning proficiency, which continues to develop through the mid20 s. ${ }^{47}$ To assess transition readiness, the Kennedy Krieger Independence Scales-Spina Bifida Version was developed as a caregiver-reported measure of self-management skills and executive functioning in youth with spina bifida. Preliminary data support its use as a reliable and valid assessment of self-care management skills. ${ }^{48}$ This holds potential value in identifying individual deficiencies in self-management and executive functioning in order to personalize transition planning and readiness assessments.

Resilience, defined as the ability to respond positively to adversity, has been correlated with transition readiness in other chronic conditions. Using the Resilience Scale (RS14), a validated measure in adolescents and adults, pediatric SLE patients enrolled in a cross-sectional study completed questionnaires to assess whether resilience was associated with transition readiness via TRAQ assessment. Results indicated that TRAQ scores were significantly correlated with resilience and age, but not associated with disease duration, fatigue, anxiety, depressive symptoms, disease damage, or disease activity. ${ }^{49}$ Thus, correcting for age and other confounding factors, resilience scores seem to be correlated with transition readiness assessment scores, and it may be important to include resilience building in transition programs.

Regardless of the tool used to assess transition readiness, the AAP, ACP, and AAFP guidelines recommend providers to assess $\mathrm{Y} / \mathrm{YA}$ and family members independently to determine the level of the Y/YA's independence. ${ }^{20}$

\section{Transition planning}

Transition planning is a collaborative and fluid process which is driven by the Y/YA's medical problems and individual goals. Got Transition guidelines include examples of a HCT plan of care and suggest to regularly update the plan of care using the readiness assessment findings and to incorporate the goals and prioritized actions of the $\mathrm{Y} / \mathrm{YA}$ and their families. HCT planning also includes developing a portable medical summary and an emergency care plan that can be sent to the adult providers in advance of the Y/YA's transfer.

Timing has been shown to be a key component of transition planning. The 2011 AAP, AAFP, and ACP clinical reports recommend that initiating the first step in the transition planning process should occur at the age of 12 years and that transfer to an adult provider should occur between the ages of 18 and 21 years. ${ }^{20}$ Further emphasizing the importance of timing, the AAP, ACP, and AAFP clinical recommendations include an algorithm with guidelines for implementing specific stages of transition planning based on the most appropriate age. ${ }^{20}$ Within these recommendations, the optimal time of transfer should be individualized to the needs of each Y/YA and all primary and subspecialty care providers should be involved.

Transition planning also includes preparing youth and the parent/caregiver for legal changes in decision making, if needed, and should include obtaining necessary 
legal documents as the youth approaches the legal age of adulthood. For some youths and families, this may require referring them to legal resources about supported decision making, and for all young adults, it may require obtaining their consent to involve parents/caregivers in their care when they are legally an adult. ${ }^{73}$

Finally, transition planning involves inquiring about youth's preferences for an adult provider and assisting them in the process of finding one. A current and vetted list of adult primary and specialty care providers interested in caring for young adults should be shared with youths and families. Patients should be given information regarding insurance resources, self-care management, and culturally appropriate community supports. The key to successful transition planning is regularly updating the youth's plan of care. Transition planning can be as simple as the next steps with pertinent goals documented in a clinic note, or more involved with detailed plans of care for Y/YA with complex medical problems.

\section{Transfer/communication}

The AAP, ACP, and AAFP clinical reports emphasize the importance of communication between pediatric and adult providers for the exchange of medical and special non-medical information. ${ }^{20}$ Sharing of a medical summary along with a transfer letter with the adult provider is a core component of the ACR toolkit for pediatric providers. The transfer letter provides a brief introduction to the patient and includes personal details that will help to foster the patient-adult provider relationship. Medical summary templates for patients with JIA and SLE are available in the ACR toolkit.

There is an increasing evidence supporting the value of checklists for successful transfer of care. Checklists have long been utilized in other areas of medicine, such as surgery, with significant improvements in patient outcomes as evidenced by reductions in surgical complications and deaths. ${ }^{50}$ In adults transitioning from hospital to home, interventions that include a structured transition program with a guide or checklist have been associated with decreased rehospitalizations and medical costs. ${ }^{51}$ There has been a growing recognition of the value of checklists in the transition of youth to adult health care services. As part of the Six Core Elements of HCT, Got Transition offers a sample transfer checklist for pediatric providers to ensure that key information is sent to the adult provider. Table 1 summarizes the contents of this transfer package. For children with chronic rheumatologic disease, another transitional care checklist was recently developed by a Delphi-like international consensus panel.
This Delphi study defined what themes, specific to youth with chronic rheumatologic disease, should be addressed during the process of transition. ${ }^{52}$

\section{Transition completion/feedback}

Obtaining Y/YA feedback is an important step in the transition process; an example of a transition feedback survey is included in the Six Core Elements packages. In a pilot study implementing the Six Core Elements of HCT, transition feedback survey results of 10 pilot group members revealed inadequacies in the discussions of privacy and consent as well as in provider help in gaining self-care skills. ${ }^{18}$ In addition, the creation and distribution of a medical summary were reported in only half of the respondents. Another feedback survey was used in youth with JIA is the Mind the Gap scale that assessed satisfaction with transition to an adult provider in 10 major UK rheumatology centers. ${ }^{53}$ There are several other feedback surveys that can be used in Y/YA with many different chronic conditions to assess the preparation for transfer and transfer experience. The ADolescent Assessment of Preparation for Transition is both a reliable and a valid survey for adolescents with chronic health conditions between the ages of 16 and 17 years. It comprises 26 items including self-management, medication management, and planning for transfer of care. ${ }^{54}$ The On Your Own Feet Transfer Experience Scale (OYOFTES) consists of 18 items rated on 5-point Likert scales. Research using the OYOF-TES showed good reliability and internal consistency and underscored the importance of collaboration between pediatric and adult providers. ${ }^{55}$ The Patient Activation Measure (PAM) for Adolescents, initially tested in a large sample of adolescents with various chronic healthy conditions, measures patient engagement of adolescents with chronic conditions among a broad age range. It has good test-retest reliability and internal consistency. ${ }^{56}$ Continued analysis of patient satisfaction of their transition process and outcome will provide valuable feedback on what elements should be included in transitional care programs.

\section{Role of the adult provider in transition}

HCT does not end with transfer of the patients. Smooth integration of patients into adult practices can be one of the more difficult aspects of HCT. Usually, more than one adult appointment is required to establish and nurture the new patient-provider relationship. During the transition process, providing support for and emphasizing the role of the adult provider have been shown to be key indicators for successful transition. ${ }^{57}$ By using Delphi analysis, Suris and Akre found that $50 \%$ of the indicators for successful transition 
concentrated on engagement between the patient and the adult provider, further emphasizing the importance of the role of adult providers. ${ }^{57}$ To assist with adult rheumatologists' participation in the transition process, the ACR toolkit provides handouts specific to the adult providers and offers examples of a welcome letter.

\section{Transition models}

The Six Core Elements of HCT is a process that can be incorporated into any model of care and is not disease-specific. There have been several proposed models of transition care within the field of rheumatology; however, to date, no model has been shown to result in measurable improved outcomes. In the UK, McDonagh et al proposed a transition program based on needs assessments of focus groups, a national survey of health professionals, Delphi analysis, and retrospective case audits. ${ }^{58}$ In the analysis of the impact of the program on adolescents with JIA, significant improvements were observed in health-related quality of life and vocational preparation. However, it is unknown if these observations could be attributed to participation in the transitional care program or reflected improvement in disease activity or patient maturation. In addition, it is unknown whether these improvements persist into adulthood or if they are associated with positive long-term outcomes. ${ }^{59}$ A transition model for young adults with rheumatic disease, described by Tucker and Cabral, proposed a shared clinic between pediatric and adult rheumatologists, with assistance of a multidisciplinary team. This clinic encouraged patient independence while discouraging parental involvement. ${ }^{60}$ Another rheumatologyspecific transition model that uses a multidisciplinary team was described by Rettig and Athreya, which uses a nurse coordinator. The program comprises pre-transitional assessments and interventions that address education, vocation, and sexuality. ${ }^{61}$

To facilitate the existing models of transition of care for young people with juvenile onset of rheumatic and musculoskeletal disease, a task force of the Pediatric Rheumatology European Society (PRES)/European League Against Rheumatism (EULAR) developed the first international set of recommendations and standards. It includes 12 consensus recommendations of "essential/minimal" and "ideal/ optional" components of transitional care established via international Delphi analysis and systemic literature review. ${ }^{62}$ The recommendations are synchronous with the 2016 National Institute for Health and Care Excellence (NICE) guidance on Transition in the UK. The NICE guidelines offer recommendations that are characterized by youth involvement and partnership in the transition process and emphasize developmentally appropriate transition support as well as a strength-based practice that focuses on a young person's individual skills and experience to achieve the intended outcomes. ${ }^{74}$

\section{Evidence supporting implementation}

There is a growing evidence that a structured transition program improves outcomes, ${ }^{19}$ and there is evidence supporting the feasibility of implementing structured transition programs. Recently, the University of Rochester Medical Center integrated the Six Core Elements into their clinical practice and saw the percentage of patients tracked through transfer of care more than double compared to baseline. Pediatric providers successfully implemented the Six Core Elements of HCT by using transition readiness assessments and improved communication with adult providers through medical summaries and closed-loop exchanges. ${ }^{23}$ There has also been a recent evidence in workshops to increase transition skills in adult rheumatology providers. Combining objective standardized clinical examination sessions with skill-based transition workshops has shown to increase adult rheumatology fellows' confidence in transition skills and ability to employ best transition practices. ${ }^{63}$ Providing curriculum-based training to all rheumatologists-in-training is a system-based approach that may improve provider knowledge and confidence around transferring patients from pediatric to adult care.

\section{Measuring process and outcomes}

Many of the readiness assessments and transfer recommendations have not yet been validated against measurable outcomes of successful transition. Efforts to accomplish outcome-related research have failed to fully address the transition needs of adolescents. The general lack of specific outcome measures has been cited as problematic, as reported in a recent review of transition of care programs performed by the EULAR/PRES working group. ${ }^{64}$ There have been several proposed quantifiable outcomes to measure successful transition including uninterrupted access to health care, ${ }^{65}$ improved follow-up rates of patients transferred, and less "no show" visits. ${ }^{66}$ Huang et al studied the capability of a generic technology platform to improve disease management tasks and health-related self-efficacy in a transition cohort of patients with type 1 diabetes, inflammatory bowel disease, and cystic fibrosis and found improvement in disease management as a short-term outcome. ${ }^{21}$ In rheumatology-specific 
studies of transition outcomes in childhood onset of SLE, Son et al showed that lower educational level (less than a high school degree) was associated with increased missed appointments in the posttransition period, indicating that atrisk populations may benefit from additional guidance during the transition process. ${ }^{12}$ Recently, a UK study investigated the clinical impact of the DON'T RETARD project (Devices for Optimization of Transfer and Transition of Adolescents with Rheumatic Disorders). The DON'T RETARD transition program included a transition coordinator and provided information about JIA and medication management as well as how to manage fatigue, friendships, and schoolwork. Its effect on primary clinical outcomes including physical, psychosocial, and rheumatic-specific health status and secondary outcomes of improved quality of life were assessed in youth with JIA. Results indicated that implementation of a transition program as a brief intervention can improve the perceived health and quality of life of adolescents with JIA during the transition process. Furthermore, the study showed that a randomized controlled trial can be designed to evaluate the effectiveness of a transition program. ${ }^{67}$ Unfortunately, the study only assessed clinical differences rather than statistical significances, was performed at a single center, and did not assess long-term outcomes. Another UK study assessing transition outcomes after implementation of an evidence-based transitional program reported improvements in health-related quality of life, knowledge, satisfaction, and vocational readiness markers. ${ }^{59}$

Investigators have begun assessing the facilitation into employment of Y/YA with childhood onset of rheumatic and musculoskeletal diseases as a long-term outcome measure. There are several avenues of provider-directed guidance that patients have identified as helpful, such as access to flexible and convenient care, information and policy sign-posting, social and emotional support, skill training, and advocacy. ${ }^{68}$ Studies indicate that emphasis should be placed on provider proficiency in informational assistance and advocacy as there is often a lack of knowledge regarding antidiscrimination legislation. ${ }^{68}$ In addition, to improve employment outcomes, patients need support in disclosing their disease and its physical impact on their employment, which underscores the necessity of building their social skills and offering emotional support in a HCT program through a multidisciplinary team. ${ }^{68}$ Anxiety regarding disease disclosure is not disease-specific and interventions such as role play ${ }^{69}$ and vocational readiness counseling programs ${ }^{70}$ have been positively evaluated in other specialties. These avenues of provider-directed guidance should be supported by a strong foundation of optimal disease management. The attainment of successful employment following these interventions has not been adequately described.

An approach to assess and categorize transition measures can be done using the "Triple Aim" conceptual model. The Triple Aim was developed by the Institute for Health Care Improvement and consists of three interdependent goals: 1) to improve the individual experience of health care, 2) to improve the health of populations, and 3) to reduce the per capita costs of care. A systematic review used the Triple Aim model to categorize measures evaluating transition interventions in studies of transition of adolescents with and without chronic conditions. In the review, patient-reported health outcomes such as social and physical functioning, pain, mental health, vitality, emotional and physical roles, general perceived health, and quality of life were measured by using validated surveys. Other outcomes measured include adherence to care, follow through of medication and screening recommendations, fluctuations in drug levels, and patient mortality. ${ }^{71}$ By using the Triple Aim model to assess transition of care studies, the authors concluded that transition intervention studies measure the impact on population health, patient experience, and cost inconsistently. Thus, more consistent measures need to be implemented to better assess patient experience and outcomes. More recently, provider experience has been added, and it is now called the Quadruple Aim to measure the outcomes.

\section{Conclusion and recommendations}

To integrate a systematic approach into the transition process within the field of rheumatology, providers will need to adopt a consensus on outcome measures and a better understanding of who is at risk for poor outcomes. All youths require transition support; however, identifying the factors that put particular youth more at risk for a poor transition outcome would allow the correct amount of resources to be targeted for the appropriate population. Offering appropriate individualized patient support will likely improve some of the outcomes of Quadruple Aim. There is currently a lack of rheumatology-specific data that focuses on measuring the outcomes of Quadruple Aim, and further studies are needed regarding the improvement of patient and provider experiences and reduction of health care costs. The next steps of research in transition of care should include assessing different transition care models, using a common process of preparation, transfer, and integration, and incorporating the youth's level of needed HCT supports. In addition, further studies to assess how aspects of each model affect 
the outcomes are needed. Transition model components such as care coordinators, team models, combined clinics, and young adult clinics should be more closely evaluated. In addition, disease-specific models have been the focus of much research, the necessity of which is unknown. Finally, improving payment models for transition of care in countries that do not have publicly funded health care would assist in the implementation of transition processes. Current fee-forservice payment strategies with vignettes are outlined in a Got Transition Payment and Reimbursement Tip Sheet, ${ }^{75}$ but a more comprehensive approach beyond fee-for-service needs to be studied and best practices implemented. Although much progress has been made in understanding the barriers to transition, validating readiness assessments and the feasibility of implementing different models of transition programs, there are many unanswered questions. Future directions should focus on how to pay for transition of care in countries where important, which outcomes should be measured, how best to measure them, who is at risk for poor outcomes, and what transition model components are most significant to improve outcomes.

\section{Disclosure}

The authors report no conflicts of interest in this work.

\section{References}

1. Got Transition [homepage on the Internet]. The National Alliance to Advance Adolescent Health; 2014-2018. Available from: www.gottransition.org. Accessed February 21, 2018.

2. Van Cleave J, Gortmaker SL, Perrin JM. Dynamics of obesity and chronic health conditions among children and youth. JAMA. 2010;303(7):623-630.

3. Gortmaker SL, Sappenfield W. Chronic childhood disorders: prevalence and impact. Pediatr Clin North Am. 1984;31(1):3-18.

4. U.S. Department of Health and Human Services, Health Resources and Services Administration, Maternal and Child Health Bureau. Frequently asked questions: 2016 National Survey of Children's Health. Available from: https://mchb.hrsa.gov/data/national-surveys/data-user. Accessed May 2, 2018.

5. Shaw KL, Southwood TR, McDonagh JE; British Paediatric Rheumatology Group. User perspectives of transitional care for adolescents with juvenile idiopathic arthritis. Rheumatology (Oxford). 2004;43(6):770-778.

6. Kelly A, Niddrie F, Tunnicliffe D, et al. Patients' attitudes and experiences of transitional care in paediatric rheumatology: a systematic review of qualitative studies [abstract]. 2017 ACR/ARHP Annual Meeting; 2017. Washington, DC.

7. Nordal E, Zak M, Aalto K, et al. Ongoing disease activity and changing categories in a long-term nordic cohort study of juvenile idiopathic arthritis. Arthritis Rheum. 2011;63(9):2809-2818.

8. Selvaag AM, Aulie HA, Lilleby V, Flato B. Disease progression into adulthood and predictors of long-term active disease in juvenile idiopathic arthritis. Ann Rheum Dis. 2016;75(1):190-195.

9. Hersh A, von Scheven E, Yelin E. Adult outcomes of childhood-onset rheumatic diseases. Nat Rev Rheumatol. 2011;7(5):290-295.

10. Bitencourt N, Makris UW, Wright T, Solow EB. Time to first appointment among young adults transitioning from pediatric to adult rheumatologic care in a safety net population [abstract]. 2017 ACR/ARHP Annual Meeting; 2017. Washington, DC.
11. Hazel E, Zhang X, Duffy CM, Campillo S. High rates of unsuccessful transfer to adult care among young adults with juvenile idiopathic arthritis. Pediatr Rheumatol Online J. 2010;8:2.

12. Son MB, Sergeyenko Y, Guan H, Costenbader KH. Disease activity and transition outcomes in a childhood-onset systemic lupus erythematosus cohort. Lupus. 2016;25(13):1431-1439.

13. Katz JD, Mamyrova G, Agarwal S, et al. Parents' perception of selfadvocacy of children with myositis: an anonymous online survey. Pediatr Rheumatol Online J. 2011;9(1):10.

14. McManus MA, Pollack LR, Cooley WC, et al. Current status of transition preparation among youth with special needs in the United States. Pediatrics. 2013;131(6):1090-1097.

15. Jensen PT, Paul GV, LaCount $\mathrm{S}$, et al. Assessment of transition readiness in adolescents and young adults with chronic health conditions. Pediatr Rheumatol Online J. 2017;15(1):70.

16. Chira P, Ronis T, Ardoin S, White P. Transitioning youth with rheumatic conditions: perspectives of pediatric rheumatology providers in the United States and Canada. J Rheumatol. 2014;41(4):768-779.

17. Zisman D, White P, Chira P, Ardoin SP, Lawson EF, von Scheven E. US adult rheumatologists perspective on the transition process for young adults with rheumatic conditions [abstract]. 2015 ACR/ARHP Annual Meeting. San Francisco, CA.

18. McManus M, White P, Pirtle R, Hancock C, Ablan M, Corona-Parra R. Incorporating the six core elements of health care transition into a medicaid managed care plan: lessons learned from a pilot project. $J$ Pediatr Nurs. 2015;30(5):700-713.

19. Gabriel P, McManus M, Rogers K, White P. Outcome evidence for structured pediatric to adult health care transition interventions: a systematic review. J Pediatr. 2017;188:263-269.e215.

20. American Academy of Pediatrics, American Academy of Family Physicians, American College of Physicians, Transitions Clinical Report Authoring Group, Cooley WC, Sagerman PJ. Supporting the health care transition from adolescence to adulthood in the medical home. Pediatrics. 2011;128(1):182-200.

21. Huang JS, Terrones L, Tompane T, et al. Preparing adolescents with chronic disease for transition to adult care: a technology program. Pediatrics. 2014;133(6):e1639-e1646.

22. McManus M, White P, Barbour A, et al. Pediatric to adult transition: a quality improvement model for primary care. J Adolesc Health. 2015;56(1): 73-78.

23. Jones MR, Robbins BW, Augustine M, et al. Transfer from Pediatric to Adult Endocrinology. Endocr Pract. 2017;23(7):822-830.

24. Hickam T, White PH, Modrcin A, McManus M, Cox K. Implementing a nationally recognized pediatric-to-adult transitional care approach in a major children's hospital. Health Soc Work. 2018;43(1):3-6.

25. Wiemann CM, Hergenroeder AC, Bartley KA, et al. Integrating an EMR-based transition planning tool for CYSHCN at a children's hospital: a quality improvement project to increase provider use and satisfaction. J Pediatr Nurs. 2015;30(5):776-787.

26. Burke L, Kirkham J, Arnott J, Gray V, Peak M, Beresford MW. The transition of adolescents with juvenile idiopathic arthritis or epilepsy from paediatric health-care services to adult health-care services: a scoping review of the literature and a synthesis of the evidence. J Child Health Care. 2018 Epub Jan 1.

27. Schwartz LA, Daniel LC, Brumley LD, Barakat LP, Wesley KM, Tuchman LK. Measures of readiness to transition to adult health care for youth with chronic physical health conditions: a systematic review and recommendations for measurement testing and development. J Pediatr Psychol. 2014;39(6):588-601.

28. Stinson J, Kohut SA, Spiegel L, et al. A systematic review of transition readiness and transfer satisfaction measures for adolescents with chronic illness. Int J Adolesc Med Health. 2014;26(2):159-174.

29. Wasson J, Coleman EA. Health confidence: an essential measure for patient engagement and better practice. Fam Pract Manag. 2014;21(5): $8-12$.

30. Wood DL, Sawicki GS, Miller MD, et al. The Transition Readiness Assessment Questionnaire (TRAQ): its factor structure, reliability, and validity. Acad Pediatr. 2014;14(4):415-422. 
31. Sawicki GS, Lukens-Bull K, Yin X, et al. Measuring the transition readiness of youth with special healthcare needs: validation of the TRAQ - Transition Readiness Assessment Questionnaire. J Pediatr Psychol. 2011;36(2):160-171.

32. Mackie AS, Rempel GR, Islam S, et al. Psychosocial maturity, autonomy, and transition readiness among young adults with congenital heart disease or a heart transplant. Congenit Heart Dis. 2016;11(2):136-143.

33. Moynihan M, Saewyc EM, Whitehouse SR, Paone MC, McPherson G. Evaluation of the Transition Readiness Assessment Questionnaire (TRAQ) in a younger adolescent population [abstract]. JAdolesc Health. 2013;52(2):S71-S72.

34. Ferris ME, Harward DH, Bickford K, et al. A clinical tool to measure the components of health-care transition from pediatric care to adult care: the UNC TR(x)ANSITION scale. Ren Fail. 2012;34(6):744-753.

35. Ferris M, Cohen S, Haberman C, et al. Self-management and transition readiness assessment: development, reliability, and factor structure of the STARx questionnaire. J Pediatr Nurs. 2015;30(5):691-699.

36. Cohen SE, Hooper SR, Javalkar K, et al. Self-management and transition readiness assessment: concurrent, predictive and discriminant validation of the STARx questionnaire. J Pediatr Nurs. 2015;30(5):668-676.

37. Paone MC, Wigle M, Saewyc E. The ON TRAC model for transitional care of adolescents. Prog Transplant. 2006;16(4):291-302.

38. Klassen AF, Grant C, Barr R, et al. Development and validation of a generic scale for use in transition programmes to measure selfmanagement skills in adolescents with chronic health conditions: the TRANSITION-Q. Child Care Health Dev. 2015;41(4):547-558.

39. Betz CL. Facilitating the transition of adolescents with chronic conditions from pediatric to adult health care and community settings. Issues Compr Pediatr Nurs. 1998;21(2):97-115.

40. Betz CL. California healthy and ready to work transition health care guide: developmental guidelines for teaching health care self-care skills to children. Issues Compr Pediatr Nurs. 2000;23(4):203-244.

41. Erickson E. Childhood and Society. 2nd ed. New York, NY: Norton; 1963.

42. Piaget J, Inhelder B. The Psychology of the Child. 2nd ed. New York, NY: Basic Books; 1969.

43. Orem D. Nursing: Concepts of Practice. 5th ed. St. Louis, MO: Mosby; 1995.

44. Betz CL, Redcay G, Tan S. Self-reported health care self-care needs of transition-age youth: a pilot study. Issues Compr Pediatr Nurs. 2003;26(3):159-181.

45. Lawson EF, Hersh AO, Applebaum MA, Yelin EH, Okumura MJ, von Scheven E. Self-management skills in adolescents with chronic rheumatic disease: a cross-sectional survey. Pediatr Rheumatol Online J. 2011;9(1):35.

46. Stinson J, Spiegel L, Duffy KW, et al. Development and Testing of the Readiness for Adult Care in Rheumatology (RACER) Questionnaire for Adolescents With Rheumatic Conditions. JAdolesc Health. 2012;50(2): S89.

47. De Luca CR, Wood SJ, Anderson V, et al. Normative data from the CANTAB. I: development of executive function over the lifespan. J Clin Exp Neuropsychol. 2003;25(2):242-254.

48. Jacobson LA, Tarazi RA, McCurdy MD, et al. The Kennedy Krieger Independence Scales-Spina Bifida Version: a measure of executive components of self-management. Rehabil Psychol. 2013;58(1):98-105.

49. Lai J, Nelson L, Balboni I, Lee T, Hsu J. Resilience and Transition Readiness in Pediatric SLE Patients [abstract]. 2017 ACR/ARHP Annual Meeting. Washington, DC.

50. Haugen AS, Softeland E, Almeland SK, et al. Effect of the World Health Organization checklist on patient outcomes: a stepped wedge cluster randomized controlled trial. Ann Surg. 2015;261(5):821-828.

51. Coleman EA, Parry C, Chalmers S, Min SJ. The care transitions intervention: results of a randomized controlled trial. Arch Intern Med. 2006;166(17):1822-1828.
52. Akre C, Suris JC, Belot A, et al. Building a transitional care checklist in rheumatology: A Delphi-like survey. Joint Bone Spine. 2017 Epub Sep 28.

53. Shaw KL, Southwood TR, McDonagh JE; British Society of Paediatric and Adolescent Rheumatology. Development and preliminary validation of the 'Mind the Gap' scale to assess satisfaction with transitional health care among adolescents with juvenile idiopathic arthritis. Child Care Health Dev. 2007;33(4):380-388.

54. Sawicki GS, Garvey KC, Toomey SL, et al. Development and validation of the adolescent assessment of preparation for transition: a novel patient experience measure. J Adolesc Health. 2015;57(3):282-287.

55. van Staa A, Sattoe JN. Young adults' experiences and satisfaction with the transfer of care. J Adolesc Health. 2014;55(6):796-803.

56. Bomba F, Markwart H, Muhlan H, et al. Adaptation and validation of the German Patient Activation Measure for adolescents with chronic conditions in transitional care: $\operatorname{PAM}((\mathrm{R})) 13$ for Adolescents. Res Nurs Health. 2018;41(1):78-87.

57. Suris JC, Akre C. Key elements for, and indicators of, a successful transition: an international Delphi study. JAdolesc Health. 2015;56(6):612-618.

58. McDonagh JE, Shaw KL, Southwood TR. Growing up and moving on in rheumatology: development and preliminary evaluation of a transitional care programme for a multicentre cohort of adolescents with juvenile idiopathic arthritis. J Child Health Care. 2006;10(1):22-42.

59. McDonagh JE, Southwood TR, Shaw KL; British Society of Paediatric and Adolescent Rheumatology. The impact of a coordinated transitional care programme on adolescents with juvenile idiopathic arthritis. Rheumatology (Oxford). 2007;46(1):161-168.

60. Tucker LB, Cabral DA. Transition of the adolescent patient with rheumatic disease: issues to consider. Rheum Dis Clin North Am. 2007;33(3):661-672.

61. Rettig P, Athreya BH. Adolescents with chronic disease. Transition to adult health care. Arthritis Care Res. 1991;4(4):174-180.

62. Foster HE, Minden K, Clemente D, et al. EULAR/PReS standards and recommendations for the transitional care of young people with juvenileonset rheumatic diseases. Ann Rheum Dis. 2017;76(4):639-646.

63. Sadun R, Maslow G, Chung R, Criscione-Schreiber L. Training adult rheumatology fellows in young adult transition and transfer skills. [abstract]. 2017 ACR/ARHP Annual Meeting. Washington, DC.

64. Clemente D, Leon L, Foster H, Minden K, Carmona L. Systematic review and critical appraisal of transitional care programmes in rheumatology. Semin Arthritis Rheum. 2016;46(3):372-379.

65. Sharma N, O'Hare K, Antonelli RC, Sawicki GS. Transition care: future directions in education, health policy, and outcomes research. Acad Pediatr. 2014;14(2):120-127.

66. LaBrie N, Kiefer K, Miettunen P, et al. Review of the success of a transition clinic for young adults with rheumatic diseases. Pediatric Rheumatol Online J. 2008;6 (Suppl 1):P148.

67. Hilderson D, Moons P, Van der Elst K, Luyckx K, Wouters C, Westhovens R. The clinical impact of a brief transition programme for young people with juvenile idiopathic arthritis: results of the DON'T RETARD project. Rheumatology (Oxford). 2016;55(1):133-142.

68. Hanson H, Hart RI, Thompson B, et al. Experiences of employment among young people with juvenile idiopathic arthritis: a qualitative study. Disabil Rehabil. 2017 Epub May 13.

69. Lindsay S, McDougall C, Sanford R, Menna-Dack D, Kingsnorth $\mathrm{S}$, Adams T. Exploring employment readiness through mock job interview and workplace role-play exercises: comparing youth with physical disabilities to their typically developing peers. Disabil Rehabil. 2015;37(18):1651-1663.

70. Wolf-Branigin M, Schuyler V, White P. Improving quality of life and career attitudes of youth with disabilities:experiences from the adolescent employment readiness center. Res Soc Work Pract. 2007;17(3):324-333.

71. Prior M, McManus M, White P, Davidson L. Measuring the "triple aim" in transition care: a systematic review. Pediatrics. 2014;134(6):e1648-e1661. 
72. rheumatology.org [homepage on the Internet]. American College of Rheumatology; 2018 [updated February 22, 2018]. Available from: www. rheumatology.org/Practice-Quality/Pediatric-to-Adult-RheumatologyCare-Transition. Accessed February 22, 2018.

73. supporteddecisionmaking.org [homepage on the Internet]. National Resource Center for Supported Decision-Making. Available from: http://supporteddecisionmaking.org/content/resource-library. Accessed February 22, 2018
74. nice.org.uk [homepage on the Internet]. National Institute for Health and Care Excellence; 2018. Available from: https://www.nice.org.uk/ guidance/ng43. Accessed February 22, 2018.

75. aap.org [homepage on the Internet]. American Academy of Pediatrics; 2018. Available from: https://www.aap.org/en-us/Documents/coding. Factsheet transition coding pdf. Accessed February 22, 2018

\section{Publish your work in this journal}

Open Access Rheumatology: Research and Reviews is an international, peerreviewed, open access journal publishing original research, reports, editorials, reviews and commentaries on all aspects of clinical and experimental rheumatology in the clinic and laboratory including the following topics: Pathology, pathophysiology of rheumatological diseases; Investigation, treatment and management of rheumatological diseases; Clinical trials and novel pharmacological approaches for the treatment of rheumatological disorders. The manuscript management system is completely online and includes a very quick and fair peer-review system, which is all easy to use. Visit http://www.dovepress.com/ testimonials.php to read real quotes from published authors. 